\title{
ENFERMEIRAS REFLETINDO SOBRE SEU PROCESSO DE TRABALHO*
}

Simone Coelho Amestoy ${ }^{1}$, Maria Elisabeth Cestari² ${ }^{2}$ Maria Buss Thofehrn ${ }^{3}$, Viviane Marten Milbrath ${ }^{4}$, Adrize Rutz Porto ${ }^{5}$

RESUMO: Estudo qualitativo, descritivo e exploratório, que teve por objetivo promover a reflexão de enfermeiras sobre seu processo de trabalho. Foi realizado com 11 enfermeiras de um hospital de grande porte da região sul do Rio Grande do Sul, durante os meses de fevereiro e março de 2008, com onze enfermeiras. O grupo focal foi utilizado como técnica de coleta de dados e a Análise de Conteúdo para seu tratamento. Foram realizados dois encontros; no primeiro, abordou-se o processo de trabalho da enfermagem, suas etapas, dando-se ênfase à ação e ao discurso, conceitos propostos por Hannah Arendt. Após, abriu-se a discussão para o grupo, que participou ativamente. No segundo encontro, os dados obtidos no primeiro foram apresentados, discutidos e validados entre os participantes. Percebeu-se a importância que as enfermeiras atribuem à necessidade de refletir sobre seu processo de trabalho, por acreditarem que dessa forma as adversidades vivenciadas na instituição hospitalar poderão ser superadas.

PALAVRAS-CHAVE: Enfermagem; Trabalho; Ambiente de trabalho.

\section{NURSES REFLECTING ON THEIR WORK PROCESS}

\begin{abstract}
A qualitative, descriptive and exploratory study that aimed to promote the reflection of nurses about their work process. It was conducted in a large hospital in the southern region of Rio Grande do Sul, during the months of February and March 2008, with eleven nurses. The focus group was used as a technique for data collection and the content analysis technique for their treatment. Two meetings were carried out; the first approached the nursing work process: its stages, emphasizing the action and the discourse, concepts proposed by Hannah Arendt. After that, the group discussed actively. In the second meeting, data obtained in the first meeting were presented, discussed and validated by the participants. It was realized the importance that nurses assign to the need of reflecting on their work process, for believing that by doing that, the adversities experienced in the hospital it could be overcame.
\end{abstract}

KEYWORDS: Nursing; Work; Working environment.

\section{ENFERMERAS REFLEXIONANDO SOBRE SU PROCESO DE TRABAJO}

RESUMEN: Estudio cualitativo, descriptivo y exploratorio, que tuvo como objetivo promover la reflexión de las enfermeras acerca de su proceso de trabajo. Se llevó a cabo con 11 enfermeras de un hospital de gran porte de la región meridional de Rio Grande del Sur, durante los meses de febrero y marzo de 2008, con once enfermeras. El grupo focal fue utilizado como técnica de recolección de datos y análisis de contenido para su tratamiento. Fueron realizados dos encuentros, el primero se abordó el proceso de trabajo de enfermería, sus etapas, haciendo énfasis en la acción y el discurso, los conceptos propuestos por Hanna Arendt. Después, fue abierto el debate para el grupo, que participó activamente. En la segunda reunión presentó los datos obtenidos en la primera reunión, discutidos y validados por los participantes. Se notó la importancia que las enfermeras atribuyen la necesidad de reflexionar sobre su proceso de trabajo, creyendo que de esta manera, las dificultades experimentadas en este hospital podrían ser superada.

PALABRAS CLAVE: Enfermería; Trabajo; Ambiente de Trabajo.

\footnotetext{
*Artigo extraído da Dissertação ‘Liderança como Instrumento no Processo de Trabalho da Enfermagem’, apresentada ao Programa de Pós-Graduação em Enfermagem da Universidade Federal do Rio Grande-FURG.

${ }^{1}$ Enfermeira. Mestre em Enfermagem pela FURG.

${ }^{2}$ Enfermeira. Doutora em Enfermagem. Docente da Escola de Enfermagem da FURG.

${ }^{3}$ Enfermeira. Doutora em Enfermagem. Docente da Faculdade de Enfermagem e Obstetrícia da Universidade Federal de Pelotas-UFPel. ${ }^{4}$ Enfermeira. Mestre em Enfermagem pela FURG.

${ }^{5}$ Acadêmica de Enfermagem da Faculdade de Enfermagem e Obstetrícia da UFPel.
}

Autor correspondente:

Simone Coelho Amestoy

Universidade Federal do Rio Grande

Rua Senador Mendonça, 50/202 - 96015-200 - Pelotas-RS, Brasil

E-mail: samestoy@terra.com.br 


\section{INTRODUÇÃO}

O processo de trabalho da enfermagem exige reflexão constante em virtude de mudanças de cunho econômico, social e político, as quais afetam a estrutura das instituições de saúde. Para que estas organizações mantenham-se vivas no atual mercado de trabalho, competitivo e dinâmico, é cada vez mais visível a exploração dos trabalhadores e sua exposição a situações desgastantes que acabam ferindo a condição humana do sujeito-trabalhador ${ }^{(1)}$.

O contexto atual da saúde no país permite detectar dificuldades no processo de trabalho da enfermagem, entre elas: baixa remuneração, insuficiência de recursos humanos, déficit de materiais e escassas oportunidades de crescimento profissional $^{(2)}$. Neste sentido, a Enfermagem é uma profissão sujeita a organizações autoritárias, hierárquicas, a um processo de trabalho rotineiro, compartimentalizado, fragmentado e alienante, o que pode interferir diretamente na qualidade do cuidado $^{(3)}$. Diante disso, torna-se essencial que o enfermeiro se posicione, enquanto ser político, a fim de transformar essa realidade.

Entende-se por ser político a pessoa que utiliza, de forma coerente, a ação e o discurso no convívio social. Conforme Hannah Arendt ${ }^{(4)}$, a ação é a única atividade política por excelência, exercida diretamente entre os homens, dispensando a mediação da matéria. Convém destacar que agir, do grego archein (começar), significa tomar a iniciativa e, esta capacidade que o homem possui de agir indica que ele é capaz de realizar o improvável e o inesperado. Já o discurso atua como mediador, interferindo na teia das relações humanas. Desse modo, é a ação que torna possível a relação direta entre as pessoas e esta somente poderá tornar-se efetiva, enquanto processo coletivo, a partir da utilização autêntica do discurso ${ }^{(4)}$.

O domínio de um saber consistente sobre o próprio processo de trabalho facilita o reconhecimento das articulações internas entre a teoria e prática, permitindo o desenvolvimento de conhecimentos e de instrumentos para a realização das atividades, além de auxiliar no planejamento das ações, a partir de metas previamente determinadas, e na execução de um trabalho competente e reconhecido ${ }^{(5)}$. Esses aspectos despertam para a necessidade de reflexão, bem como a busca por maior compreensão sobre o assunto em questão.

O presente artigo é um recorte de dissertação de mestrado cuja temática abordada foi a liderança como instrumento no processo de trabalho da enfermagem $^{(1)}$. Acredita-se que os resultados obtidos justificam a elaboração do estudo, o qual teve por objetivo promover a reflexão de enfermeiras sobre seu processo de trabalho.

\section{Processo de trabalho da enfermagem}

O processo de trabalho inicia-se pelo estabelecimento de um contrato que dispõe das condições de venda da força de trabalho pelo empregado e sua compra realizada pelo empregador ${ }^{(6)}$, englobando o ser humano e a natureza. Consequentemente, o ser humano, ao modificar a natureza, está modificando sua própria natureza. Considerando esta afirmação, tornase essencial compreender os elementos que estabelecem o processo de trabalho, ou seja: “a atividade adequada a um fim, isto é, o próprio trabalho; a matéria a que se aplica o trabalho, o objeto de trabalho; os meios de trabalho, o instrumental de trabalho"(7:202).

O processo de trabalho da Enfermagem corresponde à atividade realizada pelos profissionais de enfermagem, objetivando suprir as necessidades das pessoas que precisam dos serviços de saúde. Durante as ações de cuidado compete ao enfermeiro o gerenciamento da assistência, o desenvolvimento de atividades administrativas, educativas e de pesquisa, com o intuito de aprimorar a prática profissional ${ }^{(8)}$.

Explorando melhor este contexto, entende-se por tarefa profissional o cuidado terapêutico prestado aos indivíduos, famílias e coletividade com a finalidade de preservar e restaurar a saúde. O cuidado terapêutico corresponde à essência da profissão, na medida em que o ato de cuidar configura-se numa ação com intenção terapêutica, como resolução de um problema ou necessidade das pessoas, tanto focando o âmbito preventivo quanto o curativo, ou seja, uma ação que direcione o indivíduo e a comunidade a uma vida mais saudável ${ }^{(5,9)}$.

O objeto de trabalho da Enfermagem é o ser humano que busca a execução do cuidado pela equipe de enfermagem, a qual conta com estratégias que visam à motivação e ao alcance da satisfação das necessidades humanas ${ }^{(5,9)}$. Os instrumentos de trabalho são considerados os meios utilizados como extensões do próprio corpo e da mente do trabalhador de enfermagem, com vistas a facilitar o desenvolvimento do cuidado terapêutico ${ }^{(9)}$.

Ao findar o processo de trabalho, obtém-se o produto que na Enfermagem caracteriza-se pela 
própria prestação do cuidado ${ }^{(3)}$. Finalmente, torna-se essencial salientar a força de trabalho, ou seja, a capacidade humana de executar o trabalho, que corresponde à equipe de enfermagem com suas potencialidades físicas e intelectuais ${ }^{(5,9)}$.

Desta forma, ter clara a finalidade do processo de trabalho e seus fatores constituintes é um meio de resgatar a condição humana do sujeito-trabalhador, superar a alienação vigente e auxiliar os profissionais no oferecimento de um cuidado terapêutico, humano e ético ${ }^{(10)}$.

\section{METODOLOGIA}

Estudo qualitativo do tipo descritivo e exploratório, que foi realizado durante os meses de fevereiro e março de 2008, em um hospital de grande porte localizado na região sul do Rio Grande do Sul. Participaram da pesquisa onze enfermeiras, com idade entre 23 e 39 anos, sendo 7 especialistas e uma mestranda, e com tempo de experiência profissional variando de um ano e três meses a 15 anos, e tempo de trabalho na instituição entre um e 15 anos. Todas as participantes assinaram o Termo de Consentimento Livre e Esclarecido.

Para a coleta dos dados, optou-se pelo grupo focal, técnica na qual os dados são obtidos diretamente das falas de um grupo, que relata suas experiências, sentimentos e percepções em torno de um assunto específico, de interesse coletivo(11-12). Sua utilização possibilita intensificar as informações com relação a um fenômeno, tanto no sentido de ampliação e geração de ideias, quanto no aprofundamento de uma em especial $^{(13)}$. Além disso, trata-se de uma técnica de inegável importância na saúde frente a seu aspecto social, pois se refere ao estudo de representações e relações dos diferenciados grupos da área, dos vários processos de trabalho e também da população ${ }^{(14)}$. Foram realizados dois encontros, o primeiro abordando o processo de trabalho da enfermagem e o segundo apresentando os dados emergidos no encontro anterior, bem como discuti-los com as participantes e, em seguida, validá-los.

O número ideal de integrantes de um grupo focal varia entre seis a 12 pessoas $^{(14)}$. Uma das pesquisadoras participou dos encontros exercendo a função de facilitadora, a qual teve a responsabilidade de garantir que o grupo abordasse os aspectos de interesse do estudo, além de estimular a criação de laços de confiança e de um clima favorável. Contou-se, ainda, com a presença de um observador não participante das discussões, que não fazia parte do cotidiano de trabalho das enfermeiras, a fim de preservar a neutralidade. $\mathrm{O}$ observador registrou a dinâmica de grupo e as reações dos diferentes sujeitos da pesquisa.

O local onde se realiza o grupo focal deve ser idealmente neutro, acessível, silencioso e não movimentado ${ }^{(11)}$. Com o intuito de disponibilizar às participantes um ambiente agradável, foi escolhida uma sala de estudos do próprio hospital para a realização de dois encontros. No decorrer dos mesmos, utilizouse o gravador, para que fossem registrados os dados emergidos nas discussões.

A Análise de Conteúdo ${ }^{(14)}$ foi utilizada como técnica para tratamento dos dados, por ser entendida como um meio de expressão do sujeito no qual o analista visa categorizar as palavras ou frases que aparecem com mais frequência no texto e, após, infere uma expressão que possa representá-los de forma adequada. A análise dos dados aconteceu durante todo o transcorrer do trabalho, em face da necessidade de constantes interpretações, sempre em conformidade com o objetivo do estudo. A partir da análise, emergiu um tema, o qual denominou-se "Enfermeiras refletindo sobre seu processo de trabalho".

Convém informar que para o desenvolvimento do presente estudo foram respeitados os procedimentos éticos exigidos pela Resolução 196/96 ${ }^{(15)}$ do Conselho Nacional de Saúde do Ministério da Saúde, com aprovação pelo Comitê de Ética do hospital em questão, sob o protocolo n⿳⺈ 29/2007.

\section{RESULTADOS E DISCUSSÃO}

\section{Enfermeiras refletindo sobre seu processo de trabalho}

O primeiro encontro teve como tema central o processo de trabalho da enfermagem, com duração de uma hora e dez minutos. Inicialmente, a facilitadora fez a introdução do tema, abordando a história do trabalho, bem como o processo de trabalho da enfermagem, e seus conceitos relevantes. Também enfatizou a ação e o discurso, conceitos propostos por Arendt ${ }^{(4)}$, os quais constituem recursos que as pessoas dispõem para expressar sua interioridade, ou seja, seu "eu autêntico", mediante a revelação de suas identidades, subjetividade e essência ${ }^{(16)}$. Conforme Arendt, a ação não se tornará possível no isolamento, pois estar isolado significa estar privado da capacidade de agir. Já o discurso caracteriza o ser humano por ser capaz de comunicar-se entre si, e 
não apenas comunicar necessidades meramente físicas, como sede, fome. O discurso, enfim, é mediador das ações humanas. A autora acrescenta, ainda, que os feitos humanos só possuem sentido se puderem ser dialogados, o que distingue os homens entre si, tornando-os seres políticos $^{(4)}$.

No que concerne à ação e ao discurso, pode-se destacar os seguintes depoimentos:

[...] ou a gente melhora e fica crítico ou a gente fica passivo e vai tentando ajeitar as coisas. (E3)

Quando a gente sai da faculdade, tu és a enfermeira chefe, alto padrão (risos) e a gente não têm noção do peso que as nossas palavras passam a ter. Aí, tu leva um susto, é o peso da responsabilidade. (E6)

A ação e o discurso eu acho muito importante. Tens que agir com coerência, fazer uma coisa e falar outra perante uma equipe. Tu podes perder a confiança dela. Até numa questão prática, se tu tens um funcionário realizando uma prática errada, e tu tens um bom embasamento teórico, tu vai passar confiança e tu tens como modificar. (E9)

Tais depoimentos reforçam a necessidade de resgatar a importância da ação e do discurso, por considerar a utilização coerente e consciente desses elementos, os quais são essenciais para tornar o enfermeiro um ser humano político, crítico, reflexivo, não mais passivo e conformado com as dificuldades que enfrenta em seu ambiente de trabalho.

Diante disso, cabe aos enfermeiros e demais profissionais de enfermagem colaborar, enquanto agentes políticos, nas discussões que permeiam o seu processo de trabalho, levando em consideração que suas ações, em geral, ocorrem de forma coletiva, havendo a necessidade do envolvimento e co-responsabilização de todos nos processos decisórios ${ }^{(17)}$.

O segundo encontro teve uma hora de duração e foi realizado a fim de apresentar às participantes os dados obtidos no primeiro encontro. Convém informar que as enfermeiras aproveitaram a oportunidade para discutir outros assuntos relacionados ao processo de trabalho. A liderança emergiu na discussão, sendo compreendida como uma competência profissional do enfermeiro que poderá auxiliá-lo na tomada de decisões, nos processo de negociação, no relacionamento interpessoal e na solução de conflitos decorrentes do ambiente de trabalho.
A liderança em primeiro lugar é importante para organizar o sistema de trabalho, através do estabelecimento de metas. (E5)

A liderança é fundamental para o trabalho da enfermeira. (E7)

O desenvolvimento da liderança ajuda o enfermeiro em seu processo de trabalho, por isso eu acredito que o bom líder não impõe e sim atua junto. (E8)

No cenário mundial, vivencia-se um período de intensas mudanças resultantes de contínuas transformações de origem política, econômica, filosófica e tecnológica, entre as quais se destaca a globalização, que vem influenciado as organizações, exigindo que estas se adaptem ao um ritmo de trabalho cada vez mais dinâmico e competitivo ${ }^{(18)}$.

As instituições hospitalares também foram afetadas por tais mudanças, passando a aderir a uma nova cultura organizacional, mais flexível, baseada na negociação, na redução de custos, na qualidade total e no crescimento profissional de seus colaboradores. Para atender as novas demandas, modificou-se o perfil do enfermeiro, tornando-se necessária a formação de profissionais líderes e seguros na tomada de decisões ${ }^{(19)}$.

Cabe destacar que a liderança representa um fenômeno de influência grupal, no qual é imprescindível agregar esforços individuais, para atingir as metas compartilhadas pelo grupo ${ }^{(20)}$. É também reconhecida como um instrumento no processo de trabalho do enfermeiro, que contribui para o gerenciamento das ações de enfermagem, qualidade da assistência e formação de um grupo de trabalho coeso e comprometido $^{(1)}$.

Além de potencializar as ações cuidativas, a liderança possibilita a construção de um ambiente de trabalho satisfatório, mediante o estabelecimento de vínculos profissionais saudáveis e de processos dialógicos entre o enfermeiro e os demais os integrantes da equipe de enfermagem.

Antes de finalizar esse encontro, ocorreu a validação dos dados pelas participantes do estudo. Neste momento, as enfermeiras salientaram a importância da realização de reuniões periódicas com a equipe de enfermagem.

Reunião auxilia o enfermeiro. Claro que teu posicionamento na reunião é importante, tu tens 
que ser objetiva [...]. Depois que eu fiz, eu senti que a minha liderança melhorou. (E4)

As reuniões auxiliam no desenvolvimento social do grupo, estimulam a criatividade e as aptidões dos participantes, além de favorecer a identificação dos talentos existentes na equipe de enfermagem. Todavia, para obter sucesso nas reuniões é preciso planejamento de forma sistemática, com o estabelecimento de pauta objetiva e aprovada por todos os participantes. As reuniões devem ser visualizadas como momentos de feedback; e propiciar espaços para reivindicações e reclamações, bem como momentos privilegiados nos quais há integração entre os participantes da equipe, favorecendo o aprimoramento das relações e minimizando conflitos. Tal recurso auxilia de forma significativa no estabelecimento dos vínculos profissionais $^{(9)}$.

No cotidiano dos enfermeiros que trabalham na instituição na qual o estudo foi realizado, constata-se o pouco interesse e a dificuldade dos mesmos em presidir reuniões com suas equipes. As reuniões ainda são vistas pela maioria com certo temor, sendo assim, são associadas a brigas e conflitos no ambiente de trabalho.

No entanto, elas não são necessariamente utilizadas apenas para solucionar conflitos, mas também para prevení-los, por meio de um processo comunicativo claro e franco. Portanto, reuniões periódicas podem facilitar e fortalecer a liderança do enfermeiro, contribuindo para o aumento da confiança entre os integrantes da equipe.

As participantes consideraram importante essa reflexão por acreditar que dessa forma as adversidades vivenciadas em seu cotidiano poderão ser superadas, e entre as quais destacaram: a desvalorização da profissão, a rotatividade, a falta de autonomia e de apoio institucional e o pouco incentivo ao desenvolvimento e aprimoramento profissional. Em contrapartida, elegeram a liderança e a necessidade de realizar reuniões como estratégias facilitadoras do processo de trabalho da enfermagem.

\section{CONSIDERAÇÕES FINAIS}

Através do desenvolvimento desse estudo foi possível promover a reflexão de enfermeiras sobre seu processo de trabalho, a fim de estimular tais profissionais a trabalhar em sintonia, pautadas em conhecimentos teóricos e práticos para realizar a tarefa profissional, ou seja, o cuidado terapêutico ao ser humano que necessita dos cuidados de enfermagem.

Cabe destacar que a utilização do grupo focal proporcionou às enfermeiras, juntamente com as pesquisadoras, momentos de reflexão, os quais futuramente poderão contribuir para transformações concretas nessa instituição hospitalar. Além disso, essa técnica permitiu o estabelecimento de um espaço de discussão e reflexão no qual as participantes foram incentivadas a assumir, conscientemente, sua posição de atores sociais, bem como de seres políticos, críticos, reflexivos, capazes de utilizar de forma coerente a ação e o discurso, a fim de transformar a realidade em que estão inseridas.

\section{REFERÊNCIAS}

1. Amestoy SC. Liderança como instrumento no processo de trabalho da enfermagem [dissertação]. Rio Grande(RS): Universidade Federal do Rio Grande; 2008.

2. Casate JC, Corrêa AK. Humanização do atendimento em saúde: conhecimento veiculado na literatura brasileira de enfermagem. Rev Latino-Am Enfermagem. 2005 Jan/Fev;13(1):105-11.

3. Pires D. Reestruturação produtiva e trabalho em saúde no Brasil. $2^{a}$ ed. São Paulo: Anna Blume; 2008.

4. Arendt H. Ação. $10^{a}$ ed. Rio de Janeiro: Forense Universitária; 2007. A condição humana; p. 188-255.

5. Leopardi MT. Teoria e método em assistência de enfermagem. Florianópolis: Soldasoft; 2006.

6. Braverman H. Trabalho e capital monopolista: a degradação do trabalho no século XX. Rio de Janeiro: Guanabara Koogan; 1987.

7. Marx K. Processo de trabalho e processo de produzir mais valia. São Paulo: Difel; 1985. O capital: crítica da economia política; p.201-23.

8. Galvão CM, Trevizan MA, Sawada NO. A liderança do enfermeiro no século XXI: algumas considerações. Rev Esc Enferm USP. 1998;32(4):302-6.

9. Thofehrn MB, Leopardi MT. Teoria dos vínculos profissionais: um novo modo de gestão em enfermagem. Texto Contexto Enferm. 2006 Jul/Set;15(3):409-17.

10. Amestoy SC, Schwartz E, Thofehrn MB. A humanização do trabalho para os profissionais de enfermagem. Acta Paulista Enferm. 2006 Out/Dez;19(4):444-9. 
11. Iervolino SA, Pelicioni MCF. A utilização do grupo focal como metodologia qualitativa na promoção da saúde. Rev Esc Enf USP. 2001 Jun;35(2):115-21.

12. Aschidamini IM, Saupe R. Grupo focal: estratégia metodológica qualitativa. Um ensaio teórico. Cogitare Enferm. 2004 Jan/Jun;9(1):9-14.

13. Dall'agnol CM, Trench MH. Grupos focais como estratégia metodológica em pesquisas na enfermagem. Rev Gaúcha Enferm. 1999 Jan;20(1):5-25.

14. Minayo MCS. O desafio do conhecimento: pesquisa qualitativa em saúde. $8^{\mathrm{a}}$ ed. São Paulo: Hucitec; 2004.

15. Ministério da Saúde (BR). Conselho Nacional de saúde. Resolução 196, de 10 de outubro de 1996. Diretrizes e normas regulamentadoras de pesquisa envolvendo seres humanos. Brasília: Ministério da Saúde; 1996.

16. Ortega F. Para uma política da amizade: Arendt, Derrida, Foucault. Rio de Janeiro: Relume Dumará; 2000.

17. Thofehrn MB, Amestoy SC, Leopardi MT. A dimensão da subjetividade no processo de trabalho: visão arendtiana. Cienc Cuid Saude. 2007;6(supl.2):468-73.

18. Lourenço MR. Desenvolvimento da competência em liderança na efetividade de organizações de saúde dirigidas por enfermeiros-gerentes [tese]. Ribeirão Preto (SP): Universidade de São Paulo; 2004.

19. Amestoy SC, Cestari ME, Thofehrn MB, Milbrath VM. Características que interferem na construção do enfermeiro-líder. Acta Paul Enferm. 2009;22(5):673-8.

20. Lourenço MR, Trevizan, MA. Liderança situacional: análise de estilo de enfermeiros-líderes. Acta Paul Enferm. 2002;15(1):48-52. 